\title{
Desafios da acessibilidade no ensino superior: estudo de caso na Universidade de Aveiro
}

\author{
Accessibility challenges in higher education: \\ case study in University of Aveiro
}

\section{Desafíos de la accesibilidad en la educación superior: estudío de caso en la Universidade de Aveiro}

\author{
ELISA MARIA PIVETTA* \\ ANA MARGARIDA PISCO ALMEIDA** \\ DANIELA SATOMI SAITO*** \\ VANIA RIBAS ULBRICHT $* * * *$
}

\begin{abstract}
$\diamond$
RESUMO

Este artigo apresenta um estudo de caso realizado no Gabinete Pedagógico da Universidade de Aveiro (Portugal) com o intuito de compreender o que uma instituição de ensino superior tem feito para que alunos com deficiência prossigam seus estudos, alcançando os níveis superior e de pós-graduação. Esse estudo permitiu verificar que os maiores desafios para a acessibilidade estão relacionados com a atitude pessoal, com a promoção da inclusão e com a possibilidade de acesso a uma aprendizagem flexível, independentemente do tempo e do espaço. E o resultado corrobora com as estatísticas da Organização Mundial de Saúde (OMS), mostrando que é crescente, mesmo que lento, o número de alunos com deficiência que procuram formação superior e aperfeiçoamento profissional.
\end{abstract}

Palavras-chave: Acessibilidade. Inclusão. Alunos com deficiência. Ensino superior.

\begin{abstract}
This paper presents a case study conducted with the Pedagogical Cabinet of the University of Aveiro (Portugal) aiming to find out in an educational institution, of a first world country, what a higher education institution has been done to the students with disabilities proceed in study, achieving the graduation and post-graduation levels. This study enabled to verify that the bigger challenges in accessibility are related to personal attitude, promoting inclusion, and the possibility of having a flexible learning, independent of time and space. The result also confirms the World Health Organization (WHO) statistics, showing that although slow, the number os students with disabilities searching for education in graduation and professional specialization levels is growing.
\end{abstract}

Keywords: Accessibility. Inclusion. Students with disabilities. Higher education.

\section{RESUMEN}

En este trabajo presentamos un estudio de caso realizado en el Gabinete Pedagógico de la Universidade de Aveiro (Portugal) con el objetivo de comprender que hace una instituición de educación superior para que los alumnos con discapacidades sigan sus estudios, alcanzando los niveles superior y de posgrado. El estudio ha permitido verificar que los principales desafíos para la accesibilidad están relacionados con la actitud personal, la promoción de la inclusión y la posibilidad de acceso a un aprendizaje flexible, independente del tiempo y del espacio. El resultado corrobora con las estadísticas de la Organización Mundial de Salud (OMS), que indica que es creciente, aunque despacio, el número de alumnos con discapacidades que buscan formación superior y perfeccionamiento profesional. Palabras clave: Accesibilidad. Inclusión. Alumnos con discapacidades. Enseñanza superior.

\footnotetext{
* Doutora. Universidade Federal de Santa Maria, Santa Maria, RS. E-mail: <elisapivetta@gmail.com>.

** Doutora. Universidade de Aveiro, Aveiro, Portugal. E-mail: <marga@ua.pt $>$.

*** Doutora. Instituto Federal de Santa Catarina, Campus Palhoça, SC. E-mail: <daniela.saito@gmail.com>.

**** Doutora. Universidade Federal de Santa Catarina, Florianópolis, SC.E-mail: <vaniaulbricht@gmail.com>.
} 


\section{INTRODUÇão}

A acessibilidade tem sido uma preocupação constante nas últimas décadas. Na arquitetura e no urbanismo, nas comunicações e na informática, entre outros campos, são muitos os programas e projetos em torno dessa temática que salientam a importância de eliminar as barreiras arquitetônicas e comunicacionais em prol da acessibilidade e da inclusão.

Incluir é um ato de justiça social, assegurando condições de igualdade no exercício dos direitos e das liberdades fundamentais e promovendo a autonomia e a independência pela minimização de barreiras, sejam de comunicação, sejam de interação com o meio. O Decreto Federal no 5.296/2004 afirma que é dever prioritário, como facilitador da inclusão, que empresas e instituições de ensino disponham de atendimento a pessoas com deficiência. O referido decreto, no seu artigo 5o, parágrafo 1, inciso I, conceitua deficiente como aquele "que possui limitação ou incapacidade para o desempenho de atividade", classificando-o de acordo com as seguintes categorias: física, auditiva, visual, mental e múltipla (BRASIL, 2004). Uma crescente e contínua mudança social e cultural coloca a deficiência como algo exterior ao indivíduo (OMS, 2011).

Conforme a Lei $n^{0}$ 13.146, de 6 de julho de 2015, acessibilidade é a "possibilidade e condição de alcance para utilização, com segurança e autonomia, de espaços, mobiliários, equipamentos urbanos, edificações, transportes, informação e comunicação, inclusive seus sistemas e tecnologias". Essa mesma lei conceitua barreira como qualquer entrave ou obstáculo que limite ou impeça a participação social da pessoa e o exercício de seus direitos à acessibilidade, à liberdade de expressão, informação e comunicação (BRASIL, 2015).

De acordo com o relatório do Centro Regional de Informação das Nações Unidas (UNRIC, 2013), em países onde a expectativa de vida é superior a 70 anos, cada indivíduo viverá com uma deficiência de oito anos, em média, isto é $11,5 \%$ da sua existência. Dados como estes salientam a importância e a amplitude do tema. Para Fontes (2009, p. 77), "só uma visão capaz de perspectivar os problemas das pessoas com deficiência não como um problema individual, mas como um problema social, pode efetivamente mudar a vida das pessoas com deficiência".

Em complemento, o Programa das Nações Unidas para o Desenvolvimento (PNUD) relata que $80 \%$ das pessoas com deficiência vivem nos países em desenvolvimento. No campo educacional, $90 \%$ das crianças com deficiência não frequentam a escola (UNRIC, 2013). O fato de os países em desenvolvimento terem um percentual maior de deficientes sublinha a necessidade de elaboração de políticas públicas para minimizar o impacto que incorre sobre a educação e propiciar a recepção adequada desses alunos no sistema de ensino. Segundo o PNUD, a proporção das pessoas com deficiência é nitidamente mais elevada nos grupos com menos instrução. Em média, $19 \%$ das pessoas menos instruídas têm uma deficiência, em comparação com $11 \%$ das mais instruídas (UNRIC, 2013).

Nos países da $\mathrm{OCDE}^{1}$ (Organisation de Coopération et de Développement Économiques), entre eles Portugal, o número de pessoas com deficiência e que prosseguem os estudos até o nível superior ainda é baixo, mas esse número vêm aumentando nos últimos anos (UNESCO, 2013) em virtude das políticas de inclusão e acessibilidade que estão sendo implantadas. Nesse contexto, esse estudo teve como objetivo fazer uma investigação na Universidade de Aveiro (Portugal), para fins de verificar o que tem sido feito para que alunos com deficiência continuem seus estudos, alcançando os níveis superior e de pós-graduação.

Esta pesquisa procurou buscar informações acerca das políticas de acessibilidade no ensino superior, bem como verificar o que contribui para o desenvolvimento das políticas vigentes. Foi utilizada uma metodologia de estudo de caso, contemplando etapas relacionadas à exploração, coleta e análise de dados. O estudo é caracterizado como avaliativo e de ação, pois teve por propósito fornecer informações que auxiliem a julgar méritos de forma a contribuir para o desenvolvimento do caso por meio de feedback.

Dentro desse escopo, a seção 2 descreve conceitos de acessibilidade, suas modalidades e dimensões. A seção 3 relata a metodologia que foi utilizada para o desenvolvimento do estudo de caso e a seção 4 detalha as informações acerca da condução das etapas metodológicas definidas para esta pesquisa, apresentando o estudo de caso. A seção 5 mostra as considerações finais acerca deste estudo, finalizando com a apresentação das principais referências deste artigo.

\section{Modalidades E Dimensões DO CONCEITO DE ACESSIBILIDADE}

O conceito de acessibilidade é comumente associado a questões físicas e arquitetônicas. Todavia, esse é um conceito muito amplo e que pode ser observado a partir de diferentes prismas, assumindo, portanto, várias modalidades (SASSAKI, 2009):

\footnotetext{
1 Organização para a Cooperação e Desenvolvimento Económico é uma organização internacional de 34 países que aceitam os princípios da democracia representativa e da economia de livre mercado. A maioria dos membros da OCDE são considerados países desenvolvidos, com economias que apresentam um elevado PIB (Produto Interno Bruto) per capita e Índice de Desenvolvimento Humano.
} 
- acessibilidade arquitetônica - referente a elementos ambientais/físicos dos edifícios, espaços urbanos e meios de transporte individuais ou coletivos;

- acessibilidade comunicacional - trata da comunicação interpessoal, seja no domínio oral, gestual ou na escrita, seja em contextos analógicos ou digitais;

- acessibilidade metodológica e instrumental aborda métodos, técnicas, instrumentos e ferramentas em vários domínios, nomeadamente na educação, trabalho, ação comunitária, desporto e lazer;

- acessibilidade programática - relacionada com políticas públicas, leis, normas e regulamentos quer de natureza institucional quer empresarial;

- acessibilidade atitudinal - refere-se a preconceitos, estigmas, estereótipos e discriminações;

- acessibilidade tecnológica - voltada a uma dimensão transversal a todas as anteriores, e na qual é integrada a acessibilidade digital.

O conceito de acessibilidade digital, em especial, no que respeita à web, parte do princípio que todos os indivíduos conseguem aceder, compreender e interagir em plataformas e serviços digitais de forma efetiva, bem como participar, criar e contribuir ativamente para essas plataformas e serviços, independentemente das suas especificidades. Atender ao perfil das pessoas é uma prioridade quando são desenvolvidos serviços e conteúdos para essas plataformas, sendo igualmente fundamental aferir o grau de conformidade das mesmas com as atuais diretrizes de acessibilidade para a web propostas pelo World Wide Web Consortium, o Consórcio W3C (W3C, 2013).

Entre as diretrizes, destaca-se a relevância dos processos de redundância de informação, tal como a disponibilização da informação em formatos variados, passíveis de serem acedidos por sujeitos com diferentes competências e aptidões. Igualmente, é fundamental atender ao contexto de uso, que, muitas vezes, determina a incapacidade temporária para utilizar eficaz e autonomamente serviços e aplicações web (BERGMAN; JOHNSON, 1995). O conceito de acessibilidade deve, pois, ser entendido como uma componente do conceito de usabilidade já que, tal como indicam Passerino e Montardo (2007, p. 14), "ser acessível é permitir o uso".

Com efeito, as Tecnologias de Informação e Comunicação (TICs) apresentam um grande potencial na criação de uma sociedade mais inclusiva. As TICs são instrumentos facilitadores e motivadores, principalmente para pessoas que apresentam alguma deficiência, seja permanente ou temporária, e criam as bases para o aumento da autonomia desses sujeitos. É inquestionável o papel que os atuais recursos digitais têm no incremento dos processos de autossuficiência das pessoas com deficiência, permitindo-lhes desempenhar suas atividades pessoais, profissionais, educacionais e culturais, independentemente das suas limitações e de contextos temporais e espaciais que, até alguns anos atrás, restringiam as suas atividades.

No campo particular da educação, a modalidade de Ensino a Distância (EaD), por minimizar as barreiras espaciais e temporais, assume o papel de "componentechave" dos atuais modelos de ensino inclusivo. Destaca-se também uma forte tendência para o ensino híbrido. Segundo Johnson et al. (2014), o paradigma educacional está mudando para incluir mais aprendizagem on-line e modelos colaborativos. Segundo os autores, os alunos passam muito do seu tempo livre na internet, aprendendo e trocando informações. A aprendizagem híbrida tem o potencial de alavancar as habilidades do campo físico, através da inclusão de oportunidades da aprendizagem on-line, aproveitando o melhor dos dois ambientes.

Além do potencial das Tecnologias de Informação e Comunicação para um ensino acessível e inclusivo, existem outros fatores que contribuem para a acessibilidade e, consequentemente, para a inclusão de pessoas com deficiência nas instituições de ensino. São os fatores relacionados com os aspectos atitudinais. A esse respeito, importa observar os diferentes comportamentos e atitudes que podem ser observados como comuns, inclusive nas instituições de ensino (LIMA; SILVA, 2013):

- ignorância (desconhecer as potencialidades dos alunos com deficiência); medo e rejeição;

- percepção de menos-valia ou inferioridade (avaliar de forma depreciativa a capacidade desses alunos);

- compensação (acreditar que os alunos com deficiência devem ser compensados);

- negação (desconsiderar as deficiências do aluno com dificuldades na aprendizagem);

- comparação (comparar os alunos com e sem deficiência);

- segregação (separar os indivíduos com e sem deficiência);

- assistencialismo e superproteção.

Assim, em busca de minimizar barreiras nesse domínio atitudinal, é importante, tal como defendem Passerino e Montardo (2007), desenvolver meios e recursos acessíveis que promovam o estabelecimento de interfaces com esses indivíduos e que, consequentemente fomentem os processos de inclusão. Os autores adiantam ainda que, nessa procura pela inclusão, importa fundamentalmente valorizar "qualidade de vida, desenvolvimento humano, autonomia de renda e equidade de oportunidades e direitos" (PASSERINO; MONTARDO, 2007, p. 5). 


\section{Metodologia}

Esta pesquisa caracteriza-se como um estudo exploratório de cunho qualitativo realizado por meio de estudo de caso. De acordo com André (2005), o estudo de caso pode ser categorizado em quatro grandes grupos:

- etnográfico - que estuda o caso em profundidade por meio de observação participante;

- avaliativo - que analisa um caso ou conjunto de casos de forma profunda com o objetivo de fornecer aos atores educacionais informações que os auxiliem a julgar méritos e valores de políticas, programas ou instituições;

- educacional - que busca a compreensão da ação educativa;

- ação - que procura contribuir para o desenvolvimento do caso por meio de feedback.

Nesse sentido, este estudo de caso caracteriza-se como avaliativo e de ação, pois busca fornecer informações acerca das políticas de acessibilidade no ensino superior, bem como coletar feedbacks que contribuam para o desenvolvimento das políticas vigentes. A metodologia utilizada contempla etapas relacionadas a exploração, coleta de dados e análise (ANDRÉ, 2005), sendo que a Figura 1 apresenta o detalhamento das etapas metodológicas:

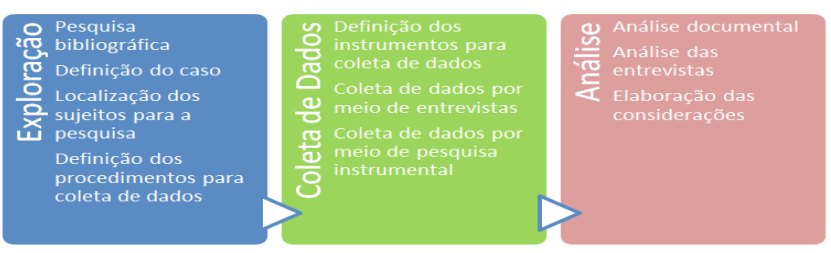

Fonte: Elaborado pelos autores, baseado em André (2005).

Figura 1. Metodologia para o estudo de caso.

$\mathrm{Na}$ fase de exploração foram realizadas as primeiras investigações acerca do tema abordado, que é a acessibilidade, de forma a viabilizar a definição do caso a ser estudado, bem como identificar os sujeitos da pesquisa para estabelecer os contatos necessários para a sua condução.

Já na fase de coleta de dados foram determinados os procedimentos de entrevista semiestruturada e pesquisa documental. A definição dos procedimentos foi seguida da elaboração do instrumento de pesquisa por meio de um roteiro previamente elaborado, contendo questionamentos básicos apoiados em teorias e hipóteses relacionadas ao tema (TRIVIÑOS, 1987). O instrumento gerado foi validado antes da coleta de dados no intuito de evitar que as perguntas tivessem mais de uma interpretação, pois interpretações diferentes podem prejudicar a análise dos dados. Esse tipo de validação é útil para que a linguagem utilizada fique mais próxima da linguagem dos respondentes, não causando fadiga e incompreensão, principalmente pelo fato de os entrevistados serem de Portugal, e o idioma apresentar diferenças, mesmo que sutis. Após a validação, o instrumento foi aplicado na coleta de dados. A pesquisa documental, por sua vez, foi realizada por meio de coleta de documentos institucionais, bem como por meio de pesquisas realizadas na internet, no intuito de identificar a repercussão das ações realizadas pela instituição.

Por fim, na fase de análise, os dados coletados por meio de entrevista foram transcritos e analisados de acordo com critérios definidos para o estudo e com as considerações finais acerca do tema geradas.

\section{ESTUDO DE CASO: Universidade De Aveiro - Portugal}

Nesta seção são detalhadas as informações acerca da condução das etapas metodológicas definidas para esta pesquisa. Importa lembrar que a pesquisa é voltada à verificação de políticas para a continuidade de estudos de alunos de graduação e pós-graduação que apresentem alguma deficiência.

$\mathrm{Na}$ etapa inicial foi realizada uma pesquisa exploratória sobre acessibilidade, visto que se trata de um assunto abrangente. Assim, foram identificadas seis dimensões de exercício da acessibilidade: arquitetônica, comunicacional, metodológica e instrumental, programática, atitudinal e tecnológica. As modalidades identificadas foram definidas como parâmetro para o estudo descrito neste artigo.

Tendo em vista os critérios e objetivos descritos, buscou-se definir como cenário de estudo uma instituição de ensino que estivesse aplicando políticas de acessibilidade e tivesse resultados referentes às ações adotadas. Dessa forma, a escolha recaiu sobre a Universidade de Aveiro (UA), em Portugal, em virtude dos seguintes fatores:

- Segundo o Instituto Nacional de Estatística (INE, 2013), Portugal possui uma população de 10.562.178. Destes, cerca de $18 \%$ declararam ter muita dificuldade, ou não conseguir realizar pelo menos uma das seis atividades diárias, que são assim categorizadas: compreender e fazer-se entender; tomar banho e vestir-se; ter memória e concentração; ver; ouvir e andar. Para a população com 65 anos ou mais, esse indicador ultrapassa $50 \%$. Todavia, é natural que o ser humano, à medida que envelhece, fique mais propenso a adquirir uma deficiência, justificando a maior concentração de deficiências nas faixas etárias mais altas. 
- Portugal compõe o grupo de países da OCDE, onde o número de pessoas com deficiência que prosseguem os estudos tem aumentado nos últimos anos (UNESCO, 2013).

- Países de primeiro mundo possuem um índice menor de pessoas com deficiência. Segundo o Programa das Nações Unidas para o Desenvolvimento, 80\% das pessoas com deficiência vivem nos países em desenvolvimento (UNRIC, 2013).

- O programa de intercâmbio apoiado pela Capes, por meio do programa de Pós-Graduação da Universidade Federal de Santa Catarina (Brasil) e pela Universidade de Aveiro (Portugal), possibilitou essa investigação.

Para compreender de que forma a universidade acolhe e acompanha os alunos com deficiência, foi realizada uma entrevista com o Gabinete Pedagógico da universidade. Esse gabinete foi criado em 1994 e surgiu da preocupação crescente com o bem-estar e sucesso escolar de todos os estudantes da Universidade de Aveiro. Assim, além da entrevista, com o intuito de caracterizar o panorama da UA em relação aos atuais processos de inclusão dos estudantes, também foram recolhidos dados documentais em posse do departamento e informações do site da universidade.

De acordo com o Gabinete Pedagógico, e tal como ilustra o Quadro 1, a quantidade de alunos com deficiência, por ano letivo, tem aumentado (ainda que se mantenha estável nos últimos três anos), confirmando as já referidas estatísticas da OMS. As necessidades desses alunos têm sido as mais diversas, desde incapacidades temporárias, doenças crônicas, deficiências motoras, auditivas e visuais, paralisia cerebral, entre outras.

Quadro 1. Número de alunos com deficiência por ano letivo na UA (2004 a 2013)

\begin{tabular}{cc}
\hline Ano letivo & Número de alunos \\
\hline $2004 / 2005$ & 16 \\
$2005 / 2006$ & 23 \\
$2006 / 2007$ & 26 \\
$2007 / 2008$ & 36 \\
$2008 / 2009$ & 47 \\
$2009 / 2010$ & 54 \\
$2010 / 2011$ & 61 \\
$2011 / 2012$ & 63 \\
$2012 / 2013$ & 62 \\
\hline
\end{tabular}

Fonte: Dados obtidos em entrevista com o Gabinete Pedagógico.

Visando a proporcionar a continuidade dos estudos desse grupo de estudantes, a Universidade de Aveiro tem se estruturado nas diversas dimensões da acessibilidade.
Assim, as próximas seções descrevem os principais aspectos considerados relevantes, identificados por meio de análise da entrevista e análise dos dados documentais.

\subsection{Acessibilidade arquitetônica}

De acordo com os dados levantados na entrevista, a universidade, fundada em 1973, apresenta uma arquitetura acessível. Segundo a representante do Gabinete Pedagógico, "os estudantes que possuem alguma deficiência da Universidade de Aveiro conseguem circular livremente nas áreas físicas do campus: a UA possui cadeiras de rodas disponíveis para empréstimo e todos os edifícios oferecem rampas de acesso e elevadores". Além disso, os edifícios estão todos interligados por calçadas niveladas, como pode ser visualizado na Figura 2.

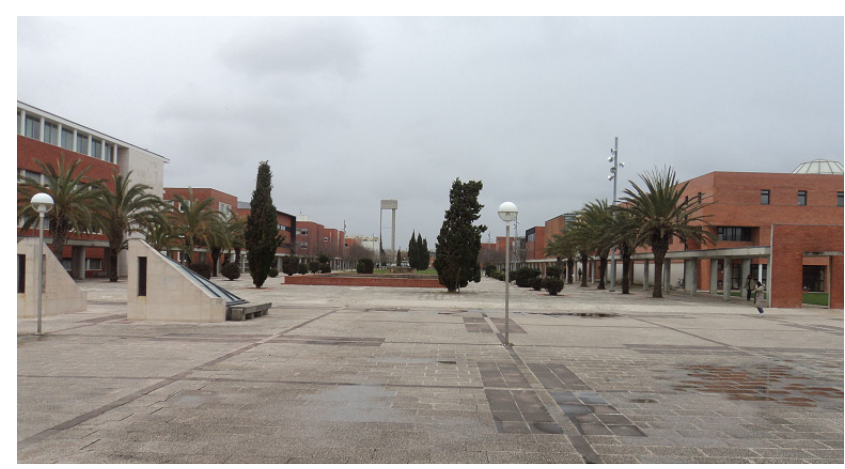

Figura 2. Universidade de Aveiro - Portugal.

Para poder utilizar os elevadores de acesso condicionado (tipicamente disponíveis apenas para funcionários, docentes, etc.), os estudantes com deficiência recebem um cartão ou código que lhes permite a circulação sem restrições nesses espaços. Um problema por resolver, mas que foi apurado e está no plano das futuras alterações da UA, são os pisos táteis para os alunos cegos. Estes são especialmente necessários nas áreas que possuem espaços abertos e que não oferecem elementos físicos (como muros ou passeios) que possam ser utilizados como referência para a mobilidade desses estudantes. No campus, também existem diversos banheiros adaptados, tipicamente utilizados por estudantes com limitações motoras.

No que respeita às salas de aula, nem todas são arquitetonicamente acessíveis. No entanto, tal situação não tem sido crítica, já que as turmas que integram alunos com deficiência podem ser remanejadas para outras salas acessíveis. No início de cada semestre, alunos que encontram problemas de acessibilidade em suas salas comunicam a situação ao Gabinete Pedagógico, em articulação com o Gabinete de Horários, que procede a troca da sala. 
É importante salientar que a grande maioria das atuais condições de acessibilidade do campus têm sido construídas/adaptadas ao longo dos anos, e motivadas pelas necessidades dos muitos estudantes com deficiência que a UA tem acolhido. Esse processo tem contribuído para criar condições mais confortáveis para todos os estudantes e para promover um espaço comum mais aberto, acessível e inclusivo.

\subsection{Acessibilidade comunicacional, metodológica, instrumental, atitudinal e digital}

Considerando as finalidades e práticas típicas de uma Instituição de Ensino Superior (IES) e a natureza dos dados recolhidos na entrevista realizada, optou-se por apresentar, numa seção única, os aspectos relativos à acessibilidade comunicacional, metodológica, instrumental, atitudinal e digital. Com efeito, essas modalidades influenciamse mutuamente e a natureza inter-relacionada dos seus efeitos não se coaduna com uma análise segmentada.

Constatou-se que na UA existem preocupações de acessibilidade comunicacional, instrumental e digital em diferentes contextos. Um deles é o da biblioteca, a qual integra, desde setembro de 2009, um serviço de apoio ao utilizador com deficiência (APOIO, 2013). Com o apoio específico de um técnico, a biblioteca assegura diferentes serviços:

- produção de documentos em formato acessível;

- postos de acesso para cegos e amblíopes, equipados com computadores com leitor de tela, sintetizador de fala, linha Braille, software específico para leitura e escrita de música em Braille;

- equipamentos mecânicos para deficientes motores.

Esse serviço integra-se ao projeto BAES (Biblioteca Aberta do Ensino Superior), uma biblioteca digital compartilhada, com conteúdos acessíveis, criada em 2006 por um consórcio de diferentes instituições do Ensino Superior Público: Universidades do Porto, Minho, Aveiro, Coimbra, Évora, Lisboa (Faculdade de Letras e de Ciências) e Trás-os-Montes e Alto Douro.

Os recursos, equipamentos e espaços existentes na Biblioteca da UA permitem que os estudantes com deficiência possam usufruir da oferta formativa da UA sem restrições, podendo utilizar esses instrumentos de apoio nas aulas ou nas avaliações. Também é possível que os alunos, que por alguma circunstância ou limitação não consigam deslocar-se à universidade, possam receber esses conteúdos via e-mail ou por outro meio mais adequado no momento.

A sala audiovisual acolhe os estudantes com deficiência nos momentos de avaliação, que são sempre efetuados com o acompanhamento da responsável pelo Gabinete Pedagógico. Nesses momentos de prova é tipicamente dado a eles um tempo extra para finalizar as avaliações, sendo ainda oferecida a possibilidade de optarem por uma avaliação diferenciada, de tipo complementar, por exemplo, uma avaliação oral, dependendo da necessidade de cada aluno.

Em relação à acessibilidade metodológica, estratégias e métodos diferenciados de atividades letivas ou avaliações são aplicados e em diferentes contextos. Um exemplo, o atual caso de um aluno da UA que está hospitalizado há dois anos e a quem a UA presta, através da web, de ferramentas, de recursos digitais e de comunicação a distância, todo o atendimento escolar; em situações de avaliação, um profissional vai até a unidade hospitalar, com o consentimento dos médicos e do hospital, realizar a avaliação do aluno. Outro exemplo é o de uma aluna que sofreu um acidente e ficou aproximadamente sete meses em casa, acamada, residindo a 200 quilômetros da universidade, sem interromper seus estudos. Em ambos os casos, o e-mail tem se revelado uma ferramenta fundamental, já que possibilita aos professores enviar materiais, tais como enunciados de exercícios, que posteriormente são devolvidos pelos alunos para correção.

Destaca-se no campo da acessibilidade atitudinal o caso de um estudante com paralisia cerebral, cuja vivência acadêmica tem sido fundamental para motivá-lo e apoiálo: como ele não consegue comer autonomamente com as suas próprias mãos são os colegas, amigos e voluntários do Gabinete Pedagógico que o ajudam no refeitório da universidade. Igualmente, nesse âmbito atitudinal, é importante ressaltar o fato de os estudantes com deficiência da UA irem a eventos culturais acompanhados, sem custos para o acompanhante. O Gabinete Pedagógico estabeleceu um conjunto de parcerias com entidades culturais, recreativas e artísticas da cidade que, dessa forma, concedem a entrada grátis nos seus eventos (teatro, concertos, etc.) para o acompanhante do aluno, que está voluntariamente auxiliando.

Os estudantes com deficiência da UA podem também participar em algumas atividades extracurriculares, como é o caso da "vela adaptada", praticada na Ria de Aveiro (laguna). A iniciativa é fruto de uma parceria entre os Serviços de Ação Social, Associação Acadêmica e Sporting Clube de Aveiro. Dois estudantes com deficiência que praticam a modalidade obtiveram importantes resultados em regatas nacionais. Destacam-se ainda o grupo de dança inclusiva da UA, constituído há cerca de três anos e composto por estudantes com e sem deficiência, assim como a organização de jogos de basquetebol em cadeira de rodas, abertos a toda a comunidade e que têm contado também com a participação de jogadores com e sem deficiência. Recentemente, foi estabelecida uma parceria da Universidade de Aveiro (UA) com a Câmara Municipal de Aveiro para permitir que a 
experiência acumulada pela universidade nesse campo traga contribuições ao município no âmbito das áreas prioritárias do campo da Mobilidade e Acessibilidade do seu Plano de Desenvolvimento Social.

Outro caso meritório é de uma aluna com uma doença altamente incapacitante, que não lhe permite sair de casa, e que bem ilustra os esforços da UA em promover a sua inclusão educativa e acadêmica e as já referidas diferentes modalidades de acessibilidade descritas nesta seção (comunicacional, metodológica, instrumental, atitudinal e digital). Para isto a UA criou condições específicas de acesso múltiplo à vida universitária, considerando que ela não consegue deslocar-se ao campus, estudando na sua própria residência (a cerca de seis quilômetros da universidade). A aluna já fez o curso de Licenciatura e atualmente é aluna de um curso de especialização de longa duração. Do ponto de vista das estratégias utilizadas para operacionalizar o apoio dado a esse caso, destacam-se: a utilização sistemática do software Skype $^{2}$ e e-mail, assim como a digitalização e envio de toda a bibliografia necessária.

No campo atitudinal é importante relatar que a aluna tem participado das atividades e rituais acadêmicos, como o batismo do caloiro. Nesses momentos, os colegas deslocam-se à casa da estudante e realizam as atividades na sua residência. Outro exemplo é o das Tunas $^{3}$, que também atuam na casa da estudante. Assim, a universidade realiza o movimento inverso, oportunizando a aprendizagem e a participação do aluno em atividades acadêmicas e culturais.

\subsection{Lógicas de diferenciação, apoio voluntário e inclusão}

Além dos relatos de casos em que a UA promove as diferentes dimensões de acessibilidade, é importante salientar, tal como referiu a responsável pelo Gabinete Pedagógico, que a UA promove atendimento e acompanhamento a todos os estudantes que se dirijam a esse gabinete. Assim, em uma lógica de inclusão e acesso universal, e tal como frisa-a entrevistada: “[...] não temos um gabinete específico para pessoas com deficiência, nós não queremos um gabinete separado e os alunos também não querem”. E continua, “[...] se houvesse um gabinete só para alunos com problemas, com deficiência, há alunos que nunca mais viriam". O gabinete funciona de forma integrada: "Não dá para ser separado [...] nós não queremos, eu não quero, enquanto eu estiver aqui vou lutar contra isto". Observa-se que o atendimento pedagógico é realizado a todos, no mesmo local, não existindo uma

\footnotetext{
${ }^{2}$ No início do semestre haviam sido instaladas câmeras de vídeo na sala de aula, mas tal estratégia demonstrou ser pouco eficaz.

3 Grupo de universitários músicos.
}

sala especial para atender alunos com deficiência. Essa estratégia faz com que os alunos que necessitam de atendimento diferenciado não se sintam constrangidos ao procurar ajuda, criando um contexto inclusivo e aberto a uma grande diversidade de alunos. Tal não configura um gueto fechado, exclusivo para alunos com deficiência, mas antes um espaço aberto e flexível com potencial de acolhimento a todos os alunos.

Outro ponto que merece destaque é que a UA não tem professores de apoio, que estejam especialmente dedicados a esses estudantes. De acordo com a responsável pelo gabinete, um professor que tem um aluno com deficiência em uma turma "[...] é um professor que tem mais trabalho [...] não ganham mais por isto, não tem redução na carga de trabalho". A entrevistada complementa: "[...] porque pessoas com deficiência exigem geralmente mais dedicação". Dessa forma, considerando a inexistência de professores de apoio, o Gabinete Pedagógico conta com um grupo de voluntários (cerca de 60 pessoas, entre estudantes, professores e funcionários) que têm um papel primordial para o sucesso no acompanhamento desses casos. Como afirma a entrevistada, sem os voluntários, "[...] a UA seria menos inclusiva, pois o trabalho deles é essencial". Essa é realidade da maioria das instituições de ensino. Por isso, é importante que esse comportamento apresentado pelo Gabinete Pedagógico seja adotado por outras instituições a fim de buscar voluntários para atender à demanda, que é constante e crescente, motivando as pessoas com deficiência a permanecer e continuar seus estudos.

São princípios e atitudes de solidariedade, apoio voluntário e inclusão que formam a base de sustentação do modelo de funcionamento do gabinete referenciado. Os relatos expostos neste artigo são exemplos de acessibilidade atitudinal, tanto por parte dos alunos como dos professores, colegas e funcionários, sendo que a tecnologia (acessibilidade comunicacional e digital) assume um papel igualmente fundamental, viabilizando a comunicação e o apoio a distância.

Professores, alunos, funcionários e voluntários são, portanto, os principais agentes desse modelo. A tecnologia, por sua vez, apresenta-se como o meio privilegiado para mediar os processos nas situações em que o deslocamento-à UA estão limitados. Possibilitam, nesses casos, a criação de contextos acadêmicos em tempos e espaços não restritos ao campus e favorecendo a participação em processos de troca de informações, geração de conhecimento e, principalmente, promoção da inclusão.

\section{CONSIDERAÇões FINAIS}

Este artigo procurou analisar, compilar e relatar informações referentes a diferentes dimensões de 
acessibilidade de uma instituição de ensino superior de Portugal, a Universidade de Aveiro. Por meio deste estudo, constatou-se que o Gabinete Pedagógico da universidade atua na perspectiva de uma pedagogia inclusiva (e não de uma pedagogia da deficiência), sem discriminação e sem barreiras, visando a levar o ensino a todos, indistintamente. Apesar de a Universidade de Aveiro ter quase meio século, os dados que puderam ser recuperados, no que diz respeito ao número de alunos com deficiência, são somente a partir do ano de 2004. Todavia, observou-se que nesses últimos dez anos o número tem aumentado significantemente.

Muito pode ser feito para incluir alunos com deficiência no meio acadêmico. No entanto, é vital que toda a sociedade compreenda que, para além de políticas públicas, fundos e verbas para intervenções arquitetônicas, ou contratação de profissionais, pouco se consegue se não houver boa vontade das pessoas. Ultrapassadas as principais barreiras no campo da infraestrutura física e assegurados os meios de comunicação e interação digital a distância, o sucesso de uma universidade inclusiva reside no âmbito atitudinal.

Em 1994, com a Declaração de Salamanca (UNESCO, 1994), foram lançadas as bases para a educação inclusiva; contudo, são muitas as barreiras atitudinais que ainda prevalecem nos ambientes escolares. Portanto, merece destaque o trabalho que a UA tem desenvolvido no sentido de minimizar as barreiras atitudinais e de criar novos e diferenciados contextos temporais e espaciais que possibilitem a todos os alunos usufruir de uma formação educacional nos níveis de graduação e pósgraduação. Contribui, dessa forma, para a construção de uma comunidade mais acolhedora e de uma sociedade inclusiva.

Destaca-se também o papel que a tecnologia tem exercido nas iniciativas de acessibilidade e inclusão na UA. Muitas das mudanças implementadas na universidade tem sido apoiadas por soluções tecnológicas que permitem diluir os tradicionais limites e restrições espaço-temporais que são, tantas vezes, barreiras para alguns dos alunos com deficiência. Com os benefícios da tecnologia, e de forma articulada e muitas vezes interdependente, evidencia-se o papel primordial dos professores e a capacidade de trabalhar em contextos diferenciados para apoiar esses alunos em momentos de dificuldades. Para o sucesso do modelo inclusivo, alia-se aos fatores já elencados o envolvimento dos alunos, de voluntários, de técnicos administrativos e da comunidade em geral.

A escola, enquanto contexto de referência dos processos de ensino-aprendizagem, consolidação dos saberes e preparação para a vida ativa, deve ser um lugar privilegiado de promoção da acessibilidade e inclusão e da não discriminação. Nesse cenário, deve, igualmente, assumir um papel ativo na implementação de lógicas de mudança, nomeadamente no campo atitudinal. Para tal, não basta conhecer os seus alunos e as suas necessidades específicas mas, fundamentalmente, promover o envolvimento pessoal e o sentimento humanitário. Fatores que poderão ter um papel determinante na geração de mudanças e transformações, quer na comunidade acadêmica, quer nos contextos sociais mais alargados desses indivíduos.

Por fim, este estudo mostra que promover a acessibilidade envolve, antes de tudo, remover barreiras atitudinais e fomentar o respeito por todos os seres humanos, independentemente das suas condições ou especificidades. Com efeito, "não é a distinção física ou sensorial que determina a humanização ou desumanização do homem. Suas limitações ou ilimitações são determinadas social e historicamente" (BIANCHETTI; FREIRE, 2004, p. 66).

\section{REFERÊNCIAS}

ANDRÉ, Marli Elisa Dalmazo Afonso de. Estudo de caso em pesquisa e avaliação educacional. Brasília: Liber Livro, 2005. APOIO. Apoio ao utilizador com necessidades especiais, Universidade de Aveiro, 2013. Disponível em: < http://portal. doc.ua.pt/baes/>. Acesso em: 10 jun. 2013.

BERGMAN, Eric; JOHNSON, Earl. Towards accessible human-computer interaction. In: NIELSEN, J. (Ed.). Advances in Human-Computer Interaction. New Jersey: Ablex Publishing Corporation, 1995. Vol. 5, p. 87-113.

BIANCHETTI, Lucídio; FREIRE, Ida Mara (orgs.). Um olhar sobre a diferença: interação, trabalho e cidadania. 6. ed. São Paulo: Papirus. 2004.

BRASIL. Decreto no 5.296, de 2 de dezembro de 2004. Regulamenta as leis nos 10.048 , de 8 de novembro de 2000 , que dá prioridade de atendimento às pessoas que especifica, e 10.098, de 19 de dezembro de 2000, que estabelece normas gerais e critérios básicos para a promoção da acessibilidade das pessoas portadoras de deficiência ou com mobilidade reduzida, e dá outras providências.

BRASIL. Lei no 13.146, de 6 de julho de 2015. Lei Brasileira de Inclusão da Pessoa com Deficiência (Estatuto da Pessoa com Deficiência).

UNRIC. Centro Regional de Informação das Nações Unidas. 2013. Disponível em: <http://www.unric.org/pt/pessoas-comdeficiencia/5459>. Acesso em: 15 jun. 2013.

FONTES, Fernando. Pessoas com deficiência e políticas sociais em Portugal: Da caridade à cidadania social. Revista Crítica de Ciências Sociais, v. 86, p. 73-93, set. 2009.

INE. Instituto Nacional de Estatística. 2013. Disponível em: $<$ http://censos.ine.pt/xportal/xmain?xpid=CENSOS\&xpgid=ce nsos2011_apresentacao>. Acesso em: 07 jun. 2013.

JOHNSON, L. et al. NMC horizon report: 2014 higher education edition. Austin, Texas: The New Media Consortium, 2014. 
LIMA, Francisco J.; SILVA, Fabiana Tavares dos Santos. Barreiras atitudinais: obstáculos à pessoa com feficiência na escola. 2013. Disponível em: <http://www.adiron.com.br/site/ uploads/File/Barreiras\%20Atitudinais.pdf>. Acesso em: 07 jun. 2013.

OMS, Relatório mundial sobre a deficiência. 2011. Linguísticos. São Paulo. Disponível em: <http://apps.who. int/iris/bitstream/10665/44575/4/9788564047020 por.pdf>. Acesso em: nov. 2015.

PASSERINO, Liliana Maria; MONTARDO, Sandra Portella. Inclusão social via acessibilidade digital: proposta de inclusão digital para pessoas com necessidades especiais. Revista da Associação Nacional dos Programas de Pós-Graduação em Comunicação, v. 8, abril 2007, p. 1-18. Disponível em: $<$ http://compos.org.br/seer/index.php/e-compos/article/ viewFile/144/145>. Acesso em: 17 jun. 2013.
SASSAKI, Romeu Kazumi. Inclusão: acessibilidade no lazer, trabalho e educação. Revista Nacional de Reabilitação (Reação). São Paulo, ano XII, p. 10-16, mar./abr. 2009.

TRIVIÑOS, Augusto N. S. Introdução à pesquisa em ciências sociais: a pesquisa qualitativa em educação. São Paulo: Atlas, 1987.

UNESCO. Declaração de Salamanca e enquadramento da acção na área das Necessidades Educativas Especiais. [S.1]: UNESCO, 1994. Disponível em: <http://unesdoc.unesco.org/ images/0013/001393/139394por.pdf>. Acesso em: 01 jun. 2013.

W3C. World Wide Web Consortium. 2013. Disponível em: <http://www.w3.org/standards/webdesign/accessibility>. Acesso em: 10 jun. 2013.

Submetido em: 25/07/2016

Aprovado em: 29/07/2016 